Palavras chave:

Tectona grandis

Serapilheira

Macronutrientes

Histórico:

Recebido 26/06/20I I

Aceito 24/07/2014

Keywords:

Tectona grandis

Litter

Macronutrients

Correspondência: taniafdr@yahoo.com.br
Tania de Fátima de Deus Rosa', Walcylene Lacerda Matos Pereira Scaramuzza', Renata Gonçalves da Silva'

\section{CONCENTRAÇÃO E ACÚMULO DE NUTRIENTES EM POVOAMENTOS DE TECA NO ESTADO DE MATO GROSSO, BRASIL}

RESUMO: O conhecimento das necessidades nutricionais de uma cultura é essencial para a elaboração das recomendações de adubação. Assim, neste estudo, objetivou-se estimar a concentração e o acúmulo de nutrientes na serapilheira de teca com diferentes idades. A pesquisa foi realizada em Nossa Senhora do Livramento - MT, durante os meses de setembro de 2008 a agosto de 2009, em três talhões dos povoamentos de teca com idades de cinco, seis e sete anos, onde foram instalados 20 coletores de madeira suspensos a $30 \mathrm{~cm}$ de altura do solo, com 0,64 $\mathrm{m}^{2}$ de área. A cada 30 dias, os conteúdos dos coletores foram recolhidos e separados manualmente em folhas, galhos e miscelâneas (cascas, flores e frutos). Cada fração foi seca em estufa de circulação forçada de ar a $70^{\circ}$ $\mathrm{C}$ até peso constante, em seguida foram pesadas, moídas e acondicionadas em sacos plásticos para posterior análise dos nutrientes. A ordem de magnitude na transferência de nutrientes pela serapilheira ao solo em função das frações ficou representada para as folhas $\mathrm{Ca}>\mathrm{N}>\mathrm{Mg}>\mathrm{K}>\mathrm{P}>\mathrm{S}$; galhos $\mathrm{N}>\mathrm{Ca}>\mathrm{K}>\mathrm{Mg}>\mathrm{S}>\mathrm{P}$; e miscelânea $\mathrm{N}>\mathrm{Ca}>\mathrm{K}>\mathrm{Mg}>\mathrm{P}>\mathrm{S}$. $A$ magnitude de nutrientes nas frações correspondeu à folhas $>$ galhos $>$ miscelânea. $A$ ordem de concentração dos nutrientes e de acúmulo nas plantas foi semelhante em todas as idades: $\mathrm{Ca}>\mathrm{N}>\mathrm{K}>\mathrm{Mg}>\mathrm{P}>\mathrm{S}$.

\section{NUTRIENTS' CONCENTRATION AND ACCUMULATION IN TEAK STANDS IN THE STATE OF MATO GROSSO, BRAZIL}

ABSTRACT: The knowledge of plant nutrition is very important for fertilizer practices. The aim of this investigation was to estimate the concentrations and accumulations of nutrients in teak trees of different ages located at Nossa Senhora do Livramento, Mato Grosso State, Brazil. From September 2008 to August 2009 wood litter collectors of 0.64 $\mathrm{cm}^{2}$ were installed $30 \mathrm{~cm}$ above soil surface to collect litter material from plants in five, six and seven year old stands. Every 30 days the litter contents were manually collected and separated in three fractions: leaves, branches and miscellaneous (barks, flowers and fruits). Each fraction was dried and then weighted and chemically analyzed. The order of nutrients stocks in the leaves was $\mathrm{Ca}>\mathrm{N}>\mathrm{Mg}>\mathrm{K}>\mathrm{P}>\mathrm{S}$, in the branches was $\mathrm{N}>$ $\mathrm{Ca}>\mathrm{K}>\mathrm{Mg}>\mathrm{S}>\mathrm{P}$, and in the miscellany was $\mathrm{N}>\mathrm{Ca}>\mathrm{K}>\mathrm{Mg}>\mathrm{P}>\mathrm{S}$. The order of nutrients magnitude in the fractions was leaves $>$ branches $>$ miscellany. The order of concentration for nutrients and accumulation for plants was the same in all ages, that is, $\mathrm{Ca}>\mathrm{N}>\mathrm{K}>\mathrm{Mg}>\mathrm{P}>\mathrm{S}$. 


\section{INTRODUÇÃO}

A espécie florestal Tectona grandis Linn. f., popularmente conhecida como teca, pertence à família Lamiaceae, é uma espécie exótica que se adaptou bem no Estado de Mato Grosso (CALDEIRA; OLIVEIRA, 2008), sendo originária da Índia, Tailândia, Laos, Birmânia, Camboja, Vietnã e Indonésia (LAMPRECHT, 1990). É uma das espécies florestais mais plantadas no Brasil, com 67.329 ha em 2012, sendo que a Região CentroOeste possui $67,4 \%$ de sua produção (ASSOCIAÇÃO BRASILEIRA DOS PRODUTORES DE FLORESTAS PLANTADAS - ABRAF, 20I3).

A teca tem o seu desenvolvimento favorecido em solos aluviais profundos, bem drenados e oxigenados, férteis, com alto teor de cálcio e $\mathrm{pH}$ entre 6,5 e 7,5 (FLORESTECA, 2010; LAMPRECHT, 1990). Entretanto, o reflorestamento, muitas vezes, ocorre em solos de menor fertilidade, sendo os mais férteis reservados às atividades agropecuárias. Segundo Figueiredo (2010), os sistemas florestais têm a vantagem de retirar nutrientes dos horizontes mais profundos dos solos e promover a ciclagem de nutrientes para os horizontes superficiais, por meio da serapilheira depositada na superfície do solo.

A concentração e o conteúdo de nutrientes na serapilheira variam em função do tipo de solo, da vegetação, da densidade populacional, da habilidade da espécie em absorver, utilizar e redistribuir os nutrientes, do habitat natural e da idade das árvores (NEVES et al., 200I), sendo assim, informações sobre a concentração e o acúmulo de nutrientes na serapilheira de teca com diferentes idades, ao nível local, tornam-se cada vez mais necessárias para tomadas de decisões, visando ao aumento da produtividade. Nos primeiros anos de crescimento as árvores bem supridas de nutrientes, armazenam maior quantidade de nutrientes na biomassa, assegurando um maior estoque de nutrientes disponíveis, por meio do ciclo bioquímico (KOLM; POGGIANI, 2003).

Em estudo desenvolvido por Schumacher et al (2008), em um povoamento florestal de Hovenia dulcis Thumb., aos 18 anos de idade, em Santa Maria, RS, as folhas apresentaram maiores teores de $\mathrm{N}, \mathrm{Ca}$ e $\mathrm{Mg}$, e a casca de $\mathrm{Ca}, \mathrm{P}$ e $\mathrm{K}$, indicando que esses compartimentos são os grandes responsáveis pelo acúmulo de elementos, apesar de possuírem biomassa relativamente menor que os galhos e a madeira. Além disso, a quantidade de nutrientes acumulados apresenta o cálcio como o elemento mais abundante na floresta, sendo que na casca quantificou-se 500,8 $\mathrm{kg} \cdot \mathrm{ha}^{-1}$. Segundo Kumar et al. (2009), ao quantificarem os teores de nutrientes na biomassa aérea de plantações de teca em Udaipur, Índia, verificaram que uma maior proporção de nutrientes ocorreu na superfície do solo, refletindo as entradas maciças de nutrientes para o solo, através de serapilheira, e em geral, a concentração de nutrientes no solo diminuiu com o aumento da idade da plantação. Sendo que a os nutrientes concentraram-se nas partes reprodutivas e folhas, com menor concentração de $\mathrm{N}, \mathrm{P}, \mathrm{K}, \mathrm{Ca}, \mathrm{Mg}, \mathrm{S}$ e $\mathrm{Cl}$ encontrada na madeira. $\mathrm{O}$ teor de nutrientes na biomassa acima do solo de plantação de teca seguiu a ordem: $\mathrm{N}>\mathrm{Ca}>\mathrm{K}>\mathrm{Mg}>\mathrm{P}>\mathrm{Na}>\mathrm{S}>\mathrm{Cl}$.

Estudos sobre a dinâmica da ciclagem de nutrientes vêm sendo amplamente realizados em diversas formações florestais, principalmente, porque a serrapilheira é uma importante fonte de nutriente para a manutenção da produção das árvores, entretanto, poucos estão relacionados a teca. Diante do exposto, neste estudo, objetivou-se determinar a concentração e $o$ acúmulo de nutrientes na serapilheira de teca com diferentes idades.

\section{MATERIAL E MÉTODOS}

\section{Região de estudo}

O estudo foi realizado no município de Nossa Senhora do Livramento - MT, na fazenda Campina, localizado na microrregião Cuiabá (MATO GROSSO, 2002), cujas coordenadas geográficas são $16^{\circ} 12^{\prime}$ 04" de latitude sul e $56^{\circ} 22^{\prime} 42^{\prime \prime}$ de longitude Oeste. Conforme a classificação Köppen o clima é do tipo Aw, tropical, com estação seca de inverno. A região possui temperatura média anual de $25^{\circ} \mathrm{C}$ (CALDEIRA; OLIVEIRA, 2008), e precipitação mensal, no período de estudo, com dados coletados em estação experimental conforme a Figura I.

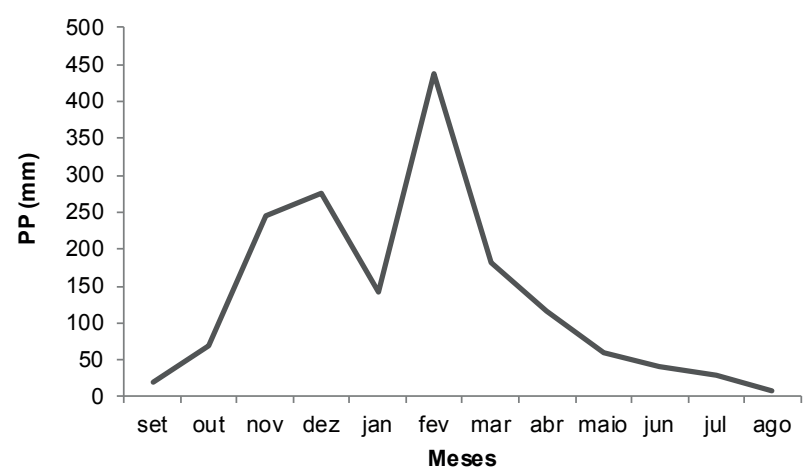

FIGURA I Precipitação mensal na área de estudo durante o período experimental.

FIGURE I Monthly precipitation in the area during the experimental period. 
De acordo com a Empresa Brasileira de Pesquisa Agropecuária - EMBRAPA (2006), o solo da área foi classificado como Argissolo Vermelho-AmareloDistrófico, com textura argilosa e relevo plano. As análises granulométricas e químicas do solo formam feitas conforme EMBRAPA (1997), cujos resultados são apresentados na Tabela I.

TABELA 1 Granulometria e características químicas do solo na profundidade $0-20 \mathrm{~cm}$

TABLE 1 Particle size and chemical characteristics of the soil at a depth of 0 to $20 \mathrm{~cm}$.

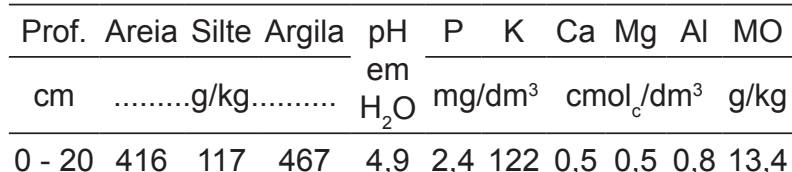

\section{Coleta e preparo do material}

A pesquisa foi instalada em três talhões dos povoamentos de teca com idades de cinco, seis e sete anos, durante os meses de setembro de 2008 a agosto de 2009.

Para a coleta do material, em cada talhão, utilizou-se uma área de um hectare $\left(10.000 \mathrm{~m}^{2}\right)$, onde foram instalados, aleatoriamente, 20 coletores de madeira, com 0,64 $\mathrm{m}^{2}$ de área, suspensos a $30 \mathrm{~cm}$ de altura do solo e confeccionados na parte central com tela de nylon (sombrite $70 \%$ ) em formato côncavo. O delineamento utilizado foi o inteiramente casualizado, sendo cada idade um tratamento.

Os conteúdos dos coletores suspensos foram recolhidos a cada 30 dias e separados, manualmente, em três frações: folhas, galhos (menores que um centímetro de diâmetro) e miscelâneas (cascas, flores e frutos). Cada fração foi seca em estufa com circulação forçada de ar à temperatura de $70^{\circ} \mathrm{C}$, até peso constante e, em seguida, foram pesadas, moídas e acondicionadas em sacos plásticos para posterior análise dos nutrientes.

\section{Concentração e acúmulo de nutrientes}

Para determinar a concentração de $\mathrm{N}$, as amostras da serapilheira depositada foram submetidas à digestão sulfúrica, conforme Silva (1999), adaptado por Rodrigues e Cabral (2008), e para os demais elementos foi utilizada a digestão nítrico-perclórica. $\mathrm{O}$ $\mathrm{N}$ foi determinado pelo método micro Kjeldahl; o $\mathrm{P}$ por colorímetria; o K por fotometria de emissão de chama; o $\mathrm{S}$ por turbidimetria; e o Ca e o Mg por espectrofotometria de absorção atômica (SILVA, 1999). O acúmulo de nutrientes foi estimado pela equação $I$, onde $M S=M S$ da fração da serapilheira $\left(\mathrm{kg} \cdot \mathrm{ha}^{-1}\right)$ e $\mathrm{CN}=$ Concentração do nutriente $\left(\mathrm{g} \cdot \mathrm{kg}^{-1}\right)$.

Acúmulo $=\frac{\text { MS.CN }}{100}$

\section{Análise estatística dos dados}

Os resultados foram analisados, estatisticamente, por meio da Análise de variância e, em caso de significância $(p<0,05)$, foi utilizado o teste Tukey $5 \%$ para comparações das médias, utilizando o aplicativo computaciovnal SISVAR (FERREIRA, 2000).

\section{RESULTADOS E DISCUSSÃO}

\section{Produção de serapilheira}

Durante os meses de setembro de 2008 a agosto de 2009 , os valores da produção da serapilheira foram maiores no talhão com sete anos com 7.280,25 kg.ha-1, seguidos pelos talhões de seis anos com $6.739,42 \mathrm{~kg} \mathrm{ha}^{-1}$, e cinco anos (6.4l 9,6I kg.ha-1). Conforme Corrêa (2005), geralmente ocorre um aumento gradativo na deposição da serapilheira até as árvores atingirem a maturidade ou fecharem as copas, sendo que, após esse estágio, pode ocorrer um ligeiro decréscimo ou uma estabilização. Em um levantamento realizado na Nigéria, em plantio de teca, Egunjobi (1974), verificou que ocorreu um aumento na queda anual de serapilheira enquanto a plantação crescia. A média da queda anual de serapilheira (folhas, sementes, flores e galhos) totalizaram $9.024 \mathrm{~kg} \cdot \mathrm{ha}^{-1}$. Kraenzel et al. (2003) ao estudarem a teca em quatro povoamentos com 20 anos de idade, no Panamá, também obtiveram valores superiores a este trabalho, com estimativa média de $7.900 \mathrm{~kg} \cdot \mathrm{ha}^{-1}$. No Brasil, Almeida (2005), avaliando a teca com cinco anos e cinco meses de idade, encontrou produção média de serapilheira semelhante $(6.700$ kg.ha- ${ }^{-1}$ ) a este trabalho.

A produção de serapilheira foi maior nos meses de agosto e setembro, final do período seco, com menor deposição nos meses de novembro e dezembro, início da época chuvosa (Figura 2). Atribuise esse resultado à característica decídua da teca. Em outra espécie florestal, Viera e Schumacher (2010a), constaram em um povoamento de Acacia mearnsii (Acácia-negra) com seis anos de idade, que a deposição de serapilheira foi mais concentrada na primavera (final da estação seca), em razão do aumento da temperatura 
média do ar e a composição de materiais reprodutivos, com uma deposição média anual de $4.320 \mathrm{~kg} \cdot \mathrm{ha}^{-1}$. Esse padrão sazonal na deposição da serapilheira também foi verificado por Gomes et al. (20I0), avaliando os efeitos da fragmentação em remanescentes florestais da Mata Atlântica, encontraram maior aporte na transição do período seco para o úmido.

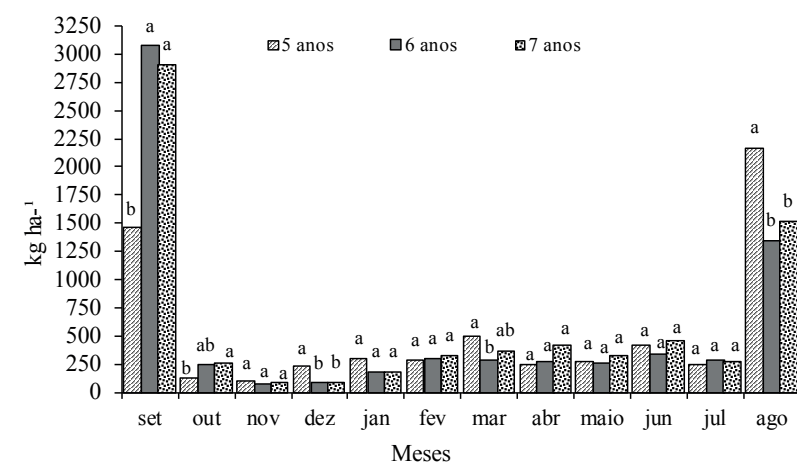

FIGURA 2 Produção média mensal de serapilheira de três talhões de teca com diferentes idades, durante o período de setembro de 2008 a agosto de 2009, no município de Nossa Senhora do Livramento - MT.

FIGURE 2 Average monthly litterfall in the three study sites of teak plantations of different ages, during September 2008 to August 2009, in the city of Nossa Senhora do Livramento - MT.

\section{Concentração de nutrientes na serapilheira}

Aidade dos talhões influenciou significativamente as concentrações de cálcio, magnésio e enxofre na serapilheira de teca. $\mathrm{Na}$ análise separada das frações da serapilheira, observou-se nas folhas e galhos um crescimento gradativo na concentração de $\mathrm{Ca}$ dos cinco $\left(19,609,92{\mathrm{~g} \cdot \mathrm{kg}^{-1}}^{-1}\right)$ aos sete anos de idade $(29,31 \mathrm{e}$ I I,77 $\left.\mathrm{g} \mathrm{kg}^{-1}\right)$, respectivamente. Todavia, para as mesmas frações, a maior concentração de $\mathrm{Mg}\left(8,03\right.$ e 3,56 g. $\left.\mathrm{kg}^{-1}\right)$ foi constatada para o talhão com 5 anos de idade. Para o enxofre observou-se o mesmo comportamento que - Mg, porém as diferenças ficaram restritas aos galhos com menor concentração aos sete anos de idade $(0,75$ $\mathrm{g} \cdot \mathrm{kg}^{-1}$ ) (Tabela 2). Exceto para P, S e K, a folha foi a fração da serapilheira que teve maior concentração de macronutrientes (Tabela 2). Para miscelânea, não houve variação significativa para a concentração de nutrientes.

O crescimento gradativo nas concentrações do cálcio nas folhas e galhos pode estar relacionado com a sua baixa mobilidade nos tecidos vegetais, onde nas folhas permanecem mesmo na sua senescência, assim, acredita-se que quanto mais velha for a folha, maior será o seu teor de cálcio (CALDEIRA et al., 2007; DIAS et al., 2002). Nesse sentido, em acículas de Pinus taeda, Viera e Schumacher (2009), constataram que a concentração do cálcio aumentou com a idade das acículas.

A variação no teor de nutrientes na serapilheira pode relacionar-se também com a participação desses nutrientes como composto estrutural, ou de moléculas orgânica, estarem associados à lignificação e constituição de paredes celulares (CALDEIRA et al., 2008; SCHUMACHER et al., 2004). Entretanto, outras características como os polifenóis e taninos devem ser estudados, uma vez que afetam a velocidade de liberação dos nutrientes e sua disponibilização para as plantas (MUSVOTO et al., 2000).

TABELA 2 Concentrações médias anuais de nutrientes em fração da serapilheira de teca, com diferentes idades, no município de Nossa Senhora do Livramento - MT.

TABLE 2 Annual average concentrations of nutrients fraction of teak litterfall, at Nossa Senhora do Livramento municipality - MT.

\begin{tabular}{|c|c|c|c|c|c|c|}
\hline \multirow{2}{*}{ Frações } & $\mathrm{N}$ & $\mathrm{P}$ & $\mathrm{K}$ & $\mathrm{Ca}$ & $\mathrm{Mg}$ & $S$ \\
\hline & \multicolumn{6}{|c|}{$\mathrm{g} \cdot \mathrm{kg}^{-1}$} \\
\hline \multicolumn{7}{|l|}{ Folhas } \\
\hline 5 anos & $13,22 a$ & $1,55 a$ & $5,36 a$ & $19,60 b$ & $8,03 a$ & $0,88 a$ \\
\hline 6 anos & $11,85 a$ & $1,42 a$ & $4,80 a$ & $25,12 a b$ & $4,85 b$ & $0,85 a$ \\
\hline 7 anos & $12,51 \mathrm{a}$ & $1,55 a$ & $4,44 a$ & $29,31 \mathrm{a}$ & $4,95 b$ & $0,79 a$ \\
\hline Médias & 12,53 & 1,51 & 4,87 & 24,68 & 5,94 & 0,84 \\
\hline CV\% & $(29)$ & (21) & $(60)$ & $(30)$ & (44) & (30) \\
\hline \multicolumn{7}{|l|}{ Galhos } \\
\hline 5 anos & $11,97 a$ & $0,28 a$ & $7,70 a$ & $9,92 b$ & $3,56 a$ & $0,90 a b$ \\
\hline 6 anos & $11,44 a$ & $0,25 a$ & $7,12 a$ & $10,75 a b$ & $2,30 b$ & $0,96 a$ \\
\hline 7 anos & $12,46 a$ & $0,24 a$ & $6,69 a$ & $11,77 a$ & $2,37 b$ & $0,75 b$ \\
\hline Médias & 11,96 & 0,26 & 7,17 & 10,81 & 2,74 & 0,87 \\
\hline CV\% & $(25)$ & $(26)$ & $(36)$ & $(24)$ & $(31)$ & $(30)$ \\
\hline \multicolumn{7}{|l|}{ Miscelânea } \\
\hline 5 anos & $11,20 a$ & $2,02 a$ & $7,12 a$ & $7,30 \mathrm{a}$ & $3,58 a$ & $1,00 \mathrm{a}$ \\
\hline 6 anos & $11,32 a$ & $2,01 a$ & $7,00 a$ & $8,77 a$ & $2,92 a$ & $1,07 a$ \\
\hline 7 anos & $11,79 a$ & $2,13 a$ & $6,50 a$ & $9,67 a$ & $2,84 a$ & $0,99 a$ \\
\hline Médias & 11,44 & 2,05 & 6,87 & 8,58 & 3,11 & 1,02 \\
\hline CV\% & $(32)$ & (17) & (28) & (30) & $(48)$ & $(42)$ \\
\hline
\end{tabular}

Médias seguidas por letras iguais nas colunas, dentro de cada fração, não diferem entre si pelo teste de Tukey a $5 \%$.

A menor concentração de magnésio na fração galhos pode ser explicadas pela participação desse elemento na constituição da clorofila a e b, por esse motivo a maior concentração é observada nas folhas, em detrimento dos outros componentes da planta (LIMA et al., 2010). Na Tabela 2, verifica-se, também, que a maior concentração de fósforo ocorreu nas miscelâneas. Viera e Schumacher (20I0a), também constataram em 
um povoamento de acácia-negra que a concentração de $P$ foi superior no material reprodutivo (flores e frutos) em comparação à fração folhas. Essa concentração é possível, pois o fósforo se move internamente na planta, também na forma de fosforilcolina, distribuindo-se facilmente pelo floema, assim, este se acumula nas folhas mais novas, flores e sementes em desenvolvimento, estimula o crescimento, acelera a maturação e ajuda a formação das sementes (FAÇANHA et al., 20I2; FERRI, 1985).

A ordem de magnitude na transferência de nutrientes pela serapilheira ao solo em função das frações nos talhões com cinco, seis e sete anos ficou representada: para as folhas $\mathrm{Ca}>\mathrm{N}>\mathrm{Mg}>\mathrm{K}>\mathrm{P}>\mathrm{S}$; galhos $\mathrm{N}>\mathrm{Ca}>\mathrm{K}>\mathrm{Mg}>\mathrm{S}>\mathrm{P}$; e miscelânea $\mathrm{N}>\mathrm{Ca}>\mathrm{K}>\mathrm{Mg}>\mathrm{P}>\mathrm{S}$. Essa magnitude de nutrientes nas frações correspondeu a folhas $>$ galhos $>$ miscelânea. A diferença na concentração dos nutrientes, nas diferentes frações de serapilheira, baseia-se, em parte, nas características da estrutura dos tecidos que predominam nos diferentes órgãos da planta e das do próprio elemento. (SCHUMACHER et al., 2004; VENEKLASS, 199I).

Aordem de contribuição dos nutrientes às plantas foi semelhante em todas as idades: $\mathrm{Ca}>\mathrm{N}>\mathrm{K}>\mathrm{Mg}>\mathrm{P}>\mathrm{S}$. A maior quantidade de cálcio e nitrogênio, provavelmente indica que a teca é uma espécie florestal muito exigente nesses nutrientes. Segundo Viera e Schumacher (20 I0b), em um povoamento de Pinus taeda, em Cambará do Sul - RS, dentre os macronutrientes estudados, o $\mathrm{Ca}$ e o $\mathrm{N}$ foram os que apresentaram maiores concentrações médias na serapilheira, com $7,88 \mathrm{~g} \cdot \mathrm{kg}^{-1}$ e $5,28 \mathrm{~g} \cdot \mathrm{kg}^{-1}$, respectivamente, seguidos, em ordem decrescente, por $\mathrm{Mg}>\mathrm{K}>\mathrm{S}>\mathrm{P}$.

O nitrogênio, o fósforo e o potássio não diferiram entre as idades, tendo apresentadas as concentrações

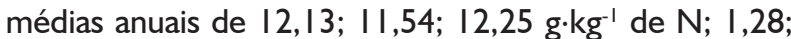
I,23; I,3। g. $\mathrm{kg}^{-1}$ de $\mathrm{P}$ e 6,72; 6,30; 5,88 g. $\mathrm{kg}^{-1}$ de $\mathrm{K}$, aos cinco, seis e sete anos, respectivamente (Tabela 2 ). Com exceção do Magnésio, resultados semelhantes a esse trabalho foram encontrados por Corrêa (2005) que constatou as seguintes concentrações médias na serapilheira depositada da teca: $12,27 \mathrm{~g} \cdot \mathrm{kg}^{-1}$ de $\mathrm{N} ; 1,22$ $\mathrm{g} \cdot \mathrm{kg}^{-1}$ de $\mathrm{P} ; 7,6 \mathrm{I} \mathrm{g} \cdot \mathrm{kg}^{-1}$ de $\mathrm{K} ; 16,60 \mathrm{~g} \cdot \mathrm{kg}^{-1}$ de Ca; I,56 $\mathrm{g} \cdot \mathrm{kg}^{-1}$ de $\mathrm{Mg}$; e $0,70 \mathrm{~g} \cdot \mathrm{kg}^{-1}$ de $\mathrm{S}$.

A importância desses resultados provém de constatação como obtidas por Borém e Ramos (2002), no qual relataram que a quantidade de $\mathrm{Ca}, \mathrm{Mg}, \mathrm{K}$ e $\mathrm{P}$ contida na serapilheira é comparável à quantidade disponível desses elementos no solo, nos primeiros 10 $\mathrm{cm}$. Viera e Schumacher (20 I b ), ressaltam que $\mathrm{K}$ e $\mathrm{Mg}$ podem sofrer lixiviação, o que contribui para explicar os baixos teores desses elementos na serapilheira.

\section{Acúmulo de nutrientes}

A sequência dos elementos devolvidos ao solo anualmente pela serapilheira foi semelhante em todas as idades, sendo maior respectivamente para o cálcio, nitrogênio, potássio, magnésio, fósforo e enxofre, Tabela 3. Dessa mesma forma Ojo et al. (20I0), avaliando a teca e uma floresta natural na Nijéira, estimou que o cálcio apresentou maior quantidade que os outros nutrientes na serapilheira.

Entretanto, Melo e Resck (2002), avaliando o retorno da serapilheira em Pinus, o nitrogênio foi o elemento de maior retorno ao solo, seguido pelo cálcio, potássio, fósforo, magnésio e enxofre. Neves et al. (200I) encontraram conteúdo médio anual de $\mathrm{N}$ para as espécies Ceiba pentandra e Virola surinamensis de 16,73 $\mathrm{kg} \cdot \mathrm{ha}^{-1}$ e $6,98 \mathrm{~kg} \cdot \mathrm{ha}^{-1}$, respectivamente.

As distribuições mensais dos acúmulos de nutrientes na serapilheira em todas as idades avaliadas acompanharam a quantidade de serapilheira produzida no período de estudo, com maior retorno de nutrientes ao solo pela deposição de serapilheira nos meses mais secos, época em que a deposição da serapilheira foi mais elevada, em razão de ter sido o período mais seco do ano e à característica caducilófia da espécie.

TABELA 3 Acúmulo médio de nutrientes, nos talhões de teca estudados, no município de Nossa Senhora do Livramento - MT. TABLE 3 Average nutrients accumulation in the studied teak stands in the municipality of Nossa Senhora do Livramento - MT.

\begin{tabular}{|c|c|c|c|c|c|c|c|c|}
\hline \multirow{2}{*}{ Idade (anos) } & \multirow{2}{*}{$\begin{array}{c}\text { Fração da } \\
\text { serapilheira }\end{array}$} & $\mathrm{N}$ & $\mathrm{P}$ & $\mathrm{K}$ & $\mathrm{Ca}$ & $\mathrm{Mg}$ & $\mathrm{S}$ & \multirow{2}{*}{$\begin{array}{c}\text { Total por } \\
\text { idade }\end{array}$} \\
\hline & & \multicolumn{6}{|c|}{ kg ha-1 } & \\
\hline \multirow{4}{*}{5} & Folhas & 24,09 & 2,89 & 11,39 & 35,41 & 11,76 & 1,50 & \\
\hline & Ramos & 1,38 & 0,14 & 0,93 & 0,93 & 0,33 & 0,08 & \\
\hline & Miscelâneas & 3,20 & 0,56 & 1,97 & 2,01 & 1,04 & 0,30 & \\
\hline & Total & 28,66 & 3,59 & 14,29 & 38,34 & 13,13 & 1,89 & 99,89 \\
\hline \multirow{4}{*}{6} & Folhas & 20,89 & 3,21 & 9,83 & 51,68 & 7,57 & 2,12 & \\
\hline & Ramos & 0,84 & 0,09 & 0,57 & 0,81 & 0,18 & 0,08 & \\
\hline & Miscelâneas & 2,39 & 0,41 & 1,41 & 1,80 & 0,63 & 0,24 & \\
\hline & Total & 24,12 & 3,71 & 11,81 & 54,30 & 8,37 & 2,44 & 104,75 \\
\hline \multirow{5}{*}{7} & Folhas & 25,20 & 3,40 & 10,08 & 62,92 & 8,14 & 1,74 & \\
\hline & Ramos & 1,16 & 0,11 & 0,68 & 1,10 & 0,22 & 0,07 & \\
\hline & Miscelâneas & 2,41 & 0,47 & 1,39 & 2,01 & 0,66 & 0,23 & \\
\hline & Total & 28,77 & 3,98 & 12,15 & 66,04 & 9,02 & 2,04 & 122,00 \\
\hline & Total geral & 81,55 & 11,27 & 38,25 & 158,68 & 30,52 & 6,37 & 326,64 \\
\hline
\end{tabular}


Sendo que o maior acúmulo foi observado no talhão com sete anos, seguido pelos talhões de seis e cinco anos, com 122,00 kg.ha-1, 104,75 kg.ha-1 e 99,89 kg.harespectivamente (Tabela 3). Conforme Ojo et al. (20l0) a quantidade de cada nutriente depende de dois fatores, um da concentração do elemento na serapilheira e da sua própria massa seca.

O total de nutrientes retornados ao solo em função da deposição da serapilheira nos três talhões foi de $326,64 \mathrm{~kg} \cdot \mathrm{ha}^{-1} \cdot \mathrm{ano}^{-1}$. A quantidade de nutrientes devolvidos ao solo demonstra a importância da serapilheira na manutenção da capacidade produtiva do sítio. Nesse sentido, Schumacher et al. (2004), descrevem que quantidades expressivas de nutrientes retornados ao solo em função da deposição da serapilheira reflete a importância da serapilheira na manutenção da sustentabilidade do ecossistema.

A magnitude de acúmulo de nutrientes para todas as idades avaliadas foi de $\mathrm{Ca}>\mathrm{N}>\mathrm{K}>\mathrm{Mg}>\mathrm{P}>\mathrm{S}$. Resultados estes, semelhantes aos obtidos por Schumacher et al. (2004) em um povoamento de Araucaria angustifolia com 17 anos de idade, em Pinhal Grande - RS, onde a magnitude de transferência dos nutrientes ao solo igual a $\mathrm{Ca}>\mathrm{N}>\mathrm{K}>\mathrm{Mg}>\mathrm{P}$, sendo as acículas as principais responsáveis pela devolução de nutrientes ao solo.

\section{CONCLUSÕES}

Aidade dos talhões influenciou significativamente as concentrações de cálcio, magnésio e enxofre na serapilheira de teca, onde se observou nas folhas e galhos um crescimento gradativo na concentração de Ca. Entretanto, para as mesmas frações, a maior concentração de $\mathrm{Mg}$ foi constatado para o talhão com 5 anos de idade.

A magnitude da concentração de nutrientes nas frações correspondeu à folhas $>$ galhos $>$ miscelânea. A ordem de concentração dos nutrientes e de acúmulo para as plantas foi semelhante em todas as idades: $\mathrm{Ca}>\mathrm{N}>\mathrm{K}>\mathrm{Mg}>\mathrm{P}>\mathrm{S}$.

\section{REFERÊNCIAS}

ALMEIDA, E. M. Determinação do estoque de Carbono em Teca (Tectona grandis L.F.) em diferentes idades. 2005. 7 I p. Dissertação (Mestrado em Agricultura Tropical) - Universidade Federal de Mato Grosso, Cuiabá, 2005.
ASSOCIAÇÃO BRASILEIRA DOS PRODUTORES DE FLORESTAS PLANTADAS. Anuário estatístico da ABRAF 2013: ano base 2012. Brasília, 2013. Disponível em: <http://www.abraflor.org.br/estatisticas/ABRAFI3/ ABRAFI3_BR.pdf $>$. Acesso em: 7 nov. 2013.

BORÉM, R. A. T.; RAMOS, D. P. Variação estacional e topográfica de nutrientes na serrapilheira de um fragmento da Mata Atlântica. Cerne, Lavras, v. 8, n. 2, p. 42-59, 2002.

CALDEIRA, S. F; OLIVEIRA, D. L. C. Desbaste seletivo em povoamentos de Tectona grandis com diferentes idades. Acta Amazônica, Manaus, v. 38, n. 2, p. 223-228, 2008.

CORRÊA, F. L. de O. Ciclagem de nutrientes em sistema agroflorestal com espécies frutíferas e florestal em Rondônia, Brasil. 2005. II0 f. Tese (Doutorado em Agronomia) - Universidade Federal de Lavras, Lavras, 2005.

DIAS, H. C. T.; FIGUEIRA, M. D.; SILVEIRA, V.; FONTES, M. A. L.; OLIVEIRA FILHO, A. T. de; SCOLFORO, J. R. $S$. Variação temporal de nutrientes na serapilheira de um fragmento de Floresta Estacional Semidecidual Montana em Lavras, Minas Gerais, Brasil. Cerne, Lavras, v. 8, n. 2, p. I-16, 2002.

EGUNJOBI, J. K. Litter fall and mineralization in a teak Tectona grandis stand. Oikos, Copenhagen, v. 25, n. 2, p. 222-226, 1974.

EMPRESA BRASILEIRA DE PESQUISA AGROPECUÁRIA. Centro Nacional de Pesquisa de Solos. Manual de métodos de análise de solos. 2. ed. Rio de Janeiro, 1997. $212 \mathrm{p}$.

EMPRESA BRASILEIRA DE PESQUISA AGROPECUÁRIA. Centro Nacional de Pesquisa de Solos. Sistema brasileiro de classificação de solos. 2. ed. Rio de Janeiro, 2006. 306 p.

FAÇANHA, A. R.; CANELLAS, L. P.; DOBBS, L. B. Nutrição mineral. In: KERBAURY, G. B. (Ed.). Fisiologia vegetal. Rio de Janeiro: Guanabara Koogan, 20I2. p. 33-50.

FERREIRA, D. F. Sistema para análise de variância para dados balanceados SISVAR. Lavras: UFLA, 2000.

FERRI, M. G. Fisiologia vegetal. São Paulo: EPU, I 985.362 p.

FIGUEIREDO, E. O. Perspectivas dos plantios de teca no Acre. Disponível em: <http://ambientes.ambientebrasil. com.br/florestal/artigos/perspectivas_dos_plantios_de_ teca no acre.html>. Acesso em: 4 jan. 2010.

FLORESTECA. Origem da Teca. Disponível em: <http:// www.floresteca.com.br/contents.asp?pid $=2>$. Acesso em: 10 jan. 2010. 
GOMES, J. M.; PEREIRA, M. G.; PIÑA-RODRIGUES, F. C. M.; PEREIRA, G. H. A.; GONDIM, F. R.; SILVA, E. M. R. da. Aporte de serapilheira e de nutrientes em fragmentos florestais da Mata Atlântica, RJ. Revista Brasileira de Ciências Agrárias, Recife, v. 5, n. 3, p. 383-39I, 2010.

KOLM, L.; POGGIANI, F. Ciclagem de nutrientes em povoamentos de Eucalyptus grandis submetidos à prática de desbastes progressivos. Scientia Forestalis, Piracicaba, n. 63, p. 79-93, jun. 2003.

KRAENZEL, M.; CASTILLO, A.; MOORE, T.; POTVIN, C. Carbon storage of harvest-age teak (Tectona grandis) plantations, Panama. Forest Ecology and Management, Amsterdam, v. 173, p. 213-225, 2003.

KUMAR, J. I.; KUMAR, R. N.; KUMAR BHOI, R.; SAJISH, P. R. Quantification of nutrient content in the aboveground biomass of teak plantation in a tropical dry deciduous forest of Udaipur, India. Journal of Forestry Science, Praha, v. 55 , n. 6, p. 25I-256, 2009.

LAMPRECHT, H. Silvicultura nos trópicos: ecossistemas florestais e respectivas espécies arbóreas: possibilidades e métodos de aproveitamento sustentado. Eschbom: $\mathrm{GmbH}$, 1990. 310 p.

LIMA, S. S. de; LEITE, L. F. C.; AQUINO, A. M. de; OLIVEIRA, F. das C.; CASTRO, A. A. J. F. Serapilheira e teores de nutrientes em argissolo sob diferentes manejos no norte do Piauí. Revista Árvore, Viçosa, v. 34, n. I, p. 75-84, 2010.

MATO GROSSO. Secretaria de Planejamento. Anuário 2002. Disponível em: <http://www.seplan.mt.gov.br/html/ anuario2002 >. Acesso em: 13 out. 2008.

MELO, J. T. de; RESCK, D. V. S. Retorno, ao solo, de nutrientes de serapilheira de Pinus no Cerrado do Distrito Federal. Planaltina: EMBRAPA Cerrados, 2002 18 p. (Boletim de Pesquisa e Desenvolvimento, 75).

MUSVOTO, C.; CAMPBELL, B. M.; KIRCHMANN, H. Decomposition and nutrient release from mango and miombo woodland litter in Zimbabwe. Soil Biology and Biochemistry, Oxford, v. 32, n. 8/9, p. IIII-III9, 2000.

NEVES, E. J. M.; MARTINS, E. G.; REISSMANN, C. B. Deposição de serapilheira e de nutrientes de duas espécies da Amazônia. Boletim Pesquisa Florestal, Colombo, n. 43, p. 47-60, jul./dez. 2001
OJO, A. F.; KADEBA, T. O. S.; KAYODE, J. Litter mass and nutrient dynamics in a transformed rainforest ecosystem in southwestern Nigeria. Bangladesh Journal of Scientific and Industrial Research, Bangladesch, v. 45, p. 35I-358, 2010.

RODRIGUES, R. C.; CABRAL, L. da S. Carboidratos nãoestruturais e compostos nitrogenados em plantas forrageiras: importância e métodos analíticos. Cuiabá: UFMT, 2008. $31 \mathrm{p}$

SCHUMACHER, M. V.; BRUN, E. J.; HERNANDES, J. I.; KÖNIG, F. G. Produção de serapilheira em uma floresta de Araucaria angustifolia (Bertol.) Kuntze no município de Pinhal Grande, RS. Revista Árvore, Viçosa, v. 28, n. I, p. 29-37, jan./fev. 2004.

SCHUMACHER, M. V.; BRUN, E. J.; ILLANA, V. B.; DISSIUTA, S. I.; AGNE, T. L. Biomassa e nutrientes em um povoamento de Hovenia dulcis Thunb., plantado na Fepagro Florestas, Santa Maria, RS. Ciência Florestal, Santa Maria, v. I8, n. I, p. 27-37, jan./mar. 2008

SILVA, F. C. da (Org.). Manual de análises químicas de solos, plantas e fertilizantes. Brasília: EMBRAPA Solos, 1999. 205 p.

VENEKLASS, E. J. Litterfall and nutrient fluxes in two montane tropical rain forests, Colômbia. Journal of Tropical Ecology, Cambridge, v. 7, p. 319-336, 1991.

VIERA, M.; SCHUMACHER, M. V. Concentração e retranslocação de nutrientes em acículas de Pinus taeda L. Ciência Florestal, Santa Maria, v. 19, n. 4, p. 375-382, out./dez. 2009.

VIERA, M.; SCHUMACHER, M. V. Deposição de serapilheira e de macronutrientes em um povoamento de Acácia-negra (Acacia mearnsii De Wild.) no Rio Grande do Sul. Ciência Florestal, Santa Maria, v. 20, n. 2, p. 225-233, abr./jun. 2010 a.

VIERA, M.; SCHUMACHER, M. V. Teores e aporte de nutrientes na serapilheira de Pinus taeda L., e sua relação com a temperatura do ar e pluviosidade. Revista Árvore, Viçosa, v. 34, n. I, p. 85-94, jan./fev. 2010 b. 